\title{
Investigation of the Use of a New Binder Material in Automotive Brake Pad
}

\author{
Banu Sugözü ${ }^{1}$, İlker Sugözü ${ }^{1 *}$ \\ 0000-0002-7798-2677, 0000-0001-8340-8121 \\ ${ }^{1}$ Mechanical Engineering Department, Faculty of Engineering, Mersin University, Mersin, 33140, Turkey
}

\begin{abstract}
In this study, the usability of waste banana peel and banana tree bark with a fibrous structure as binders was investigated experimentally. Accordingly, the amount of fiber, friction regulator, filler, abrasive and solid lubricant is fixed, and three different brake pad samples were produced by adding $10 \%$ banana peel and $10 \%$ banana tree bark powders by reducing the amount of phenolic resin. Production was carried out by conventional dry mixing method and powder metallurgy method. For this, firstly a homogeneous mixture of all ingredients is provided. The mixture transferred to the mold was pressed at room temperature firstly. Samples obtained as the first form were subjected to hot pressing in the mold again. Thus, the ability of the resin to hold all the materials together has become active. Finally, the samples were cleaned and prepared for the tests. To examine the braking performance of the produced pads, a specially designed brake tester with brake disc was used. Friction, wear, density and hardness tests of the pads were made. SEM images of friction surfaces of pads were taken and microstructures were examined. The effect of using banana waste as a binder in the brake pad on braking performance was evaluated. As a result, it was observed that banana wastes are alternative materials that can be used in brake pads.
\end{abstract}

Keywords: Binder material; Brake pad; Braking system; Waste banana

\author{
* Corresponding author \\ İlker Sugözü \\ ilkersugozu@mersin.edu.tr
}

Address: Mechanical Engineering Department, Faculty of Engineering, Mersin University, Mersin, Turkey

Research Article

Manuscript

Received 24.07.2020

Revised $\quad 25.09 .2020$

Accepted $\quad 26.09 .2020$

Doi: 10.30939/ijastech..772922

\section{Introduction}

The most important equipment in the braking systems of vehicles is the disc and pad pair. Brake pads are used to control speed by converting kinetic energy into heat energy radiating to the atmosphere in brake systems of vehicles and speed-controlled machines. The vehicles have two brake systems, disc brake and drum brake. Disc brake systems are widely used in recent years because of they have better braking performance. The pads used in brake systems provide braking by rubbing against the disc or drum surface.

Automotive brake pads are polymer matrix composite materials formed by combining many materials with different tasks [1]. These materials are generally classified as binders (matrix), reinforcements (fibers), friction modifiers, fillers, abrasives and solid lubricants [2]. The materials used in the pads have negative effects on the environment and human health during the slowing or stopping of the vehicle. During the braking of vehicles, wear particles of different chemicals, which can be toxic or mutagenic to the environment, are released [3]. After determining the negative effect of asbestos used as pad material for aquatic life and the environment, it is prohibited to use it in pad [4]. With the banning of asbestos, the search for alternative materials to asbestos has increased. Many researchers have worked on the development of asbestos-free brake pads [5-12]. The use of cocoa bean shells, palm powder, palm kernel for asbestos-free brake pads has been investigated and has been reported to be effective in braking [13-15]. Namessan et al. [16] developed a brake pad from the kenaf plant. Vlastimil et al. [17] developed an automotive brake pad using a nut shell. Aigbodion et al. [18] developed brake pads from sugar cane. Ibhadode and Dagwa [19] produced a brake pad with a palm kernel shell and made it commercially available. Yawas et al. [20] produced a brake pad with sea snail shell and stated that it could be an alternative for composite brake pads. Today, researches all over the world focus on ways to use industrial or agricultural wastes as a raw material source in pads. The use of these wastes can result in both economic and environmental control.

Phenolic resin is generally used as binder material in automotive brake pads. However, the temperature caused by friction between the disc and the pad can adversely affect the phenolic resin and the ability to hold the materials together may be partially lost. Some researchers define this situation 
as ablative wear. Therefore, asbestos-free automotive brake pad was produced by using waste banana peel and banana tree bark instead of phenolic resin, and its effect on braking performance was evaluated. Accordingly, the friction coefficient, wear, density and hardness tests of the brake pad were performed. The microstructure was examined by taking images from the wearing surface of the brake pad by scanning electron microscope (SEM).

\section{Material and Method}

\subsection{Sample Preparation}

Brake pad samples were produced using banana tree bark (MK) and banana peel (MA) in different combinations with the resin. The contents of the samples containing resin as binder, cashew, alumina, steel wool, brass swarf, copper swarf as friction modifier, graphite as lubricant and barite as filler are given in Table 1.

Table 1. Material proportions in sample content (wt. \%)

\begin{tabular}{c|c|c|c} 
Material & M-0 & MK-10 & MA-10 \\
\hline Phenolic resin & 20 & 10 & 10 \\
\hline Steel wool & 5 & 5 & 5 \\
\hline Alumina & 8 & 8 & 8 \\
\hline Brass swarf & 5 & 5 & 5 \\
\hline Graphite & 5 & 5 & 5 \\
\hline Copper swarf & 8 & 8 & 8 \\
\hline Cashew & 8 & 8 & 8 \\
\hline Banana peel & 0 & 10 & 0 \\
\hline Banana tree bark & 0 & 0 & 10 \\
\hline Barite & 41 & 41 & 41
\end{tabular}

Pads are produced by powder metallurgy method. Banana peels were dried and then powdered in a ball grinder at 200 rpm. Powdered banana peels were sieved for 15 minutes by vibrating sieve and size analysis was performed. Banana peel powders (MK) with a size of $250 \mu \mathrm{m}$ were used in the pad.

Banana tree waste was cut into pieces and dried. The dried banana tree was powdered in a ball grinder at a speed of 200 rpm. It was sieved for 15 minutes by vibrating screen and $250 \mu \mathrm{m}$ banana tree powder (MA) was obtained.

Mixtures in the ratios given in Table 1 were prepared and mixed in a mixer for 10 minutes to form a homogeneous mixture. After the mixing process, the mixture obtained was pressed in a cold press mold with a diameter of $25.4 \mathrm{~mm}$ and a height of $30 \mathrm{~mm}$ for 2 minutes at a pressure of 80 bar. In order to increase the breaking and abrasion resistance of the pad, hot pressing process was carried out in hot process mold at $150{ }^{\circ} \mathrm{C}$ with 100 bar pressure and in 10 minutes. The gases formed during the hot-pressing process were ventilated at certain intervals in order not to create pores and micro gaps in the pad.

\subsection{Experiments}

The friction coefficient and wear tests of the pads were done on a pin-on disc type test device. Detailed information about the computer-controlled test device with the disc and caliper system of a vehicle shown in Fig. 1 has been described in other studies of the authors $[21,22]$. By turning the disc on the test device with the port and the insert before the test, the negative effects that will affect the braking perfor-

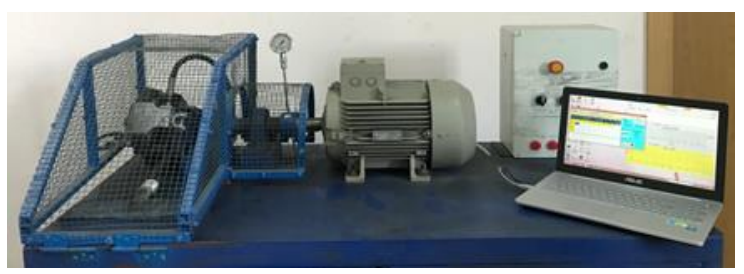

mance due to the adhesions from the previous test were eliminated.

Fig. 1. Friction test device

The performance tests of the pads were carried out at 7 bar braking pressure, $600 \mathrm{rpm}$ speed and $10.8 \mathrm{~km}$ road. In order for the pads to completely overlap with the disc surface, before the performance tests, pre-tests were performed at 3 bar braking pressure, $300 \mathrm{rpm}$ speed and for $300 \mathrm{~s}$ time.

In the pin-on-disc test device, the friction coefficient and wear tests of the pads were done and tribological properties were determined. The specific wear rate was calculated using the equation specified in TSE 555 standards [23]. Information on Equation 1 has been described in detail in other authors' work [21, 22].

$$
V=\frac{m_{1}-m_{2}}{2 \cdot \pi \cdot R_{d} \cdot n \cdot f_{m} \cdot \rho}
$$

Since the pads are porous, there are micro and macro gaps in the inner structure and they do not have a smooth geometric shape, their density is determined by Archimedes principle. Information about the Archimedes principle equation 2 has been described in detail in other studies of the authors $[21,22]$.

$$
\rho=\frac{G_{k}}{G_{k}-G_{S}}
$$

The hardness measurements of the pads were done at ambient temperature using Rockwell tester. Hardness values were determined from five different points of the wearing surfaces of the pad with a ball diameter of $6.35 \mathrm{~mm}$ and 100 $\mathrm{N}$ preload and $600 \mathrm{~N}$ full load.

\section{Results and Discussion}

In this study where banana peel powder and banana tree powder are used as an alternative to phenolic resin in brake pads, the curves of friction coefficient performance are 
shown in Fig. 2-4. During braking, the pads press on the disc surface, allowing the vehicle to stop and slow down. As a result of pressing on the disc surface, high temperatures are reached. During braking, high temperatures cause the pad to slide (fade). Conductive materials such as copper, brass swarf, and steel wool are added to content to transfer the heat generated during braking [24-26]. Air-cooled discs are widely used in vehicles to quickly eliminate the temperature on the disc. When Fig. 2-4 that the friction coefficient temperature time graphs of the produced pads are examined, the friction coefficient showed a more stability after 400 seconds due to the effect of the temperature. It showed a better braking performance due to the low temperature before the 400th second and the friction coefficient showed a higher trend. It is an important feature that the structure of the brake pads does not deteriorate due to the increase of the temperature and that the friction coefficient continues stably [27]. When the friction coefficient temperature time graphs are examined, it is seen that the MK-10 coded pad sample has a slower decrease in friction coefficient and shows a higher friction coefficient average compared to the M0 and MA-10 coded pad samples. It can be said that the MK-10 coded pad sample, which has a high coefficient of friction, increases the disc surface temperature value. It is desirable that the resin does not lose its binding properties at high temperatures in the pads [28].

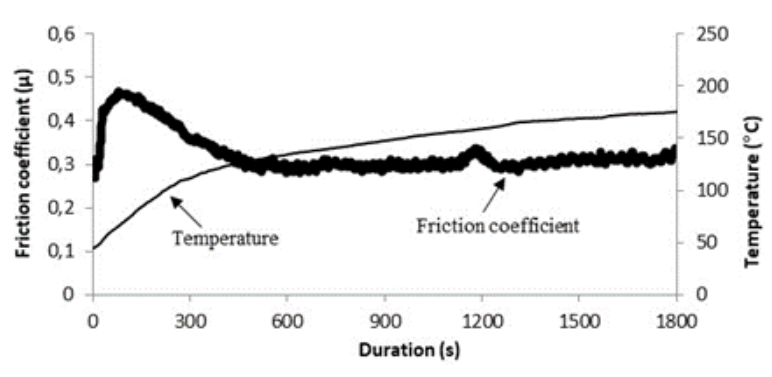

Fig. 2. Graphic of M-0 coded pad

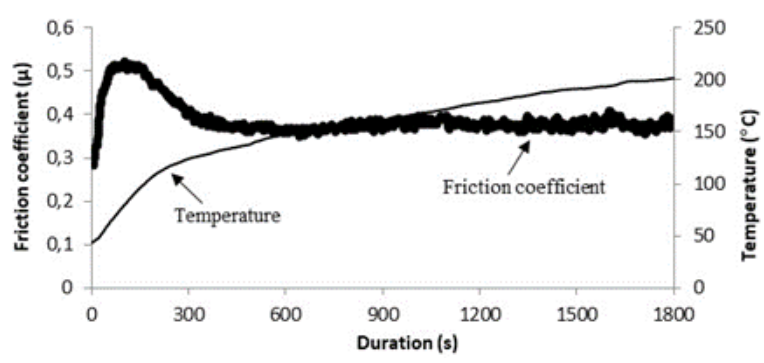

Fig. 3. Graphic of MK-10 coded pad

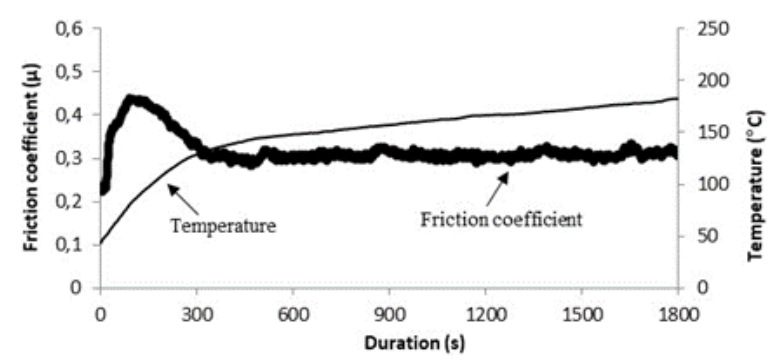

Fig. 4. Graphic of MA-10 coded pad

When Fig. 2-4 and Table 2 are examined, the highest coefficient of friction was 0.39 in the MK- 10 coded pad sample containing $10 \%$ phenolic resin and $10 \%$ banana peel. The maximum temperature generated by the MK-10 coded pad on the disc surface is determined as $202{ }^{\circ} \mathrm{C}$. The friction coefficient 0.31 in the MA-10 coded pad sample with $10 \%$ phenolic resin and $10 \%$ banana tree waste content and the maximum temperature formed on the disc surface as a result of friction was $182^{\circ} \mathrm{C}$. The average friction coefficient of the M0 coded pad sample containing only $20 \%$ phenolic resin as binder was determined as 0.33 and the temperature it formed on the maximum disc surface was determined as $178^{\circ} \mathrm{C}$. The pad containing phenolic resin as binder has been shown to perform better than banana tree powder, but lower than banana peel powder. It was determined that the banana peel used in the MK-10 coded pad positively affects the binding in the mixture and preserves the binding feature with the increase in temperature, but does not affect the friction coefficient despite the high temperature.

It is desired that the pads have a high coefficient of friction in order to have good braking performance during slowing or stopping the vehicle. High coefficient of friction occurs as a result of friction of the pads on the disc surface, but this affects the lifetime of the pad. Pads are required to exhibit high friction coefficient performance and, accordingly, low wear rate [29]. Low wear rate in pads or high resistance against wear provides longer use of the pad.

The specific wear, hardness, density and friction coefficient of the pads produced are shown in Table 2. When Table 2 is examined, it is seen that the sample with code MA-10 has the lowest wear rate. However, the low coefficient of friction, another important feature in the pad, affects the usability of the pad coded MA-10. The wear rate obtained as a result of the tests performed on the MK-10 coded pad, which has the highest friction coefficient average, was determined as $1.69 \times 10-7 \mathrm{~cm} 3 / \mathrm{Nm}$. Due to the high coefficient of friction, it is seen that it is in an acceptable value range compared to the wear rate [23].

Table 2. The results of the tests \begin{tabular}{l|l|l|l} 
Sample code & M-0 & MK-10 & MA-10
\end{tabular} 


\begin{tabular}{c|c|c|c}
\hline $\begin{array}{c}\text { The average friction co- } \\
\text { efficient }\left(\mu_{\text {avg }}\right)\end{array}$ & 0.33 & 0.39 & 0.31 \\
\hline $\begin{array}{c}\text { Specific wear rate } \times 10^{-7} \\
\left(\mathrm{~cm}^{3} / \mathrm{Nm}\right)\end{array}$ & 1.41 & 1.69 & 1.39 \\
\hline Hardness $(\mathrm{HRL})$ & 90 & 87 & 82 \\
\hline Density $\left(\mathrm{g} / \mathrm{cm}^{3}\right)$ & 1.46 & 1.50 & 1.42 \\
\hline Friction stability $(\%)$ & 68 & 75 & 70
\end{tabular}

The pad production stages are the parameters that affect the hardness and density values of the pad. The pressing pressure applied during the cold and hot-pressing process increases the density and hardness of the pad [30]. In the samples with M-0, MK-10 and MA-10 codes produced under the same production conditions, the density of the MK-10 pad was determined as $1.50 \mathrm{~g} / \mathrm{cm}^{3}$, the density of the MA-10 pad was $1.42 \mathrm{~g} / \mathrm{cm}^{3}$ and the density of the M-0 pad was 1.46 $\mathrm{g} / \mathrm{cm} 3$. The use of waste banana peel powder in combination with phenolic resin increases the density of the pad, while the use of banana tree waste powder has reduced the pad density. The hardness of the pad using phenolic resin was higher than the hardness of the pads using banana peel and banana tree powder. The best friction stability was obtained from the MK-10 coded pad sample with banana peel powder content.

The undesirable changes resulting from the separation of small particles from the surface of the material as a result of mechanical factors are reported as abrasion [31]. The microstructure reviews of the wearing surfaces of the pads are shown in Fig. 5-7.

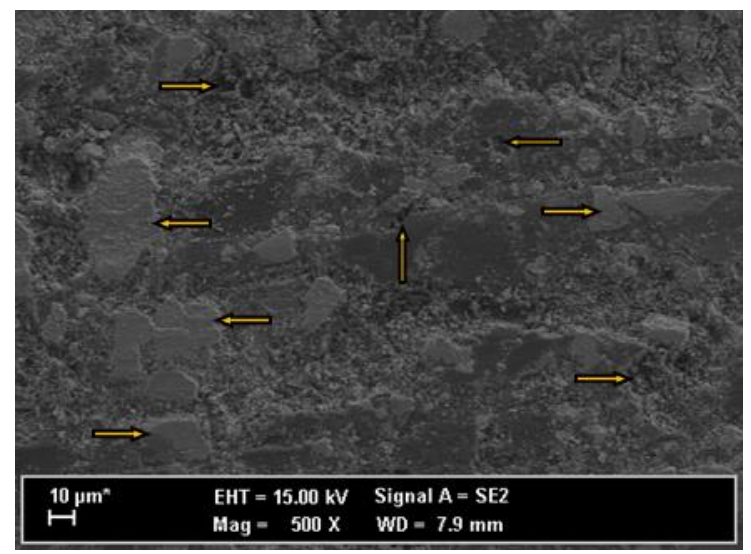

Fig. 5. SEM image of wear surface of M-0 coded pad

When Fig. 5-7 showing the structures of the wear surfaces of the pads examined by scanning electron microscopy with 10 $\mu \mathrm{m}$ and 500 magnification, it is seen that micro and macro adhesion areas are formed as a result of high mechanical stresses on the wear surfaces of the pads during braking. The abundance of adhesion areas on the wear surfaces shows that the pad shows an effective braking performance [32]. In addition, abrasions due to small pieces broken from friction materials are observed. It is seen in the figures that micro gaps are formed on the wear surface of the pad as a result of dynamic force during braking. It is seen that the adhesion areas are higher in the MK-10 pad sample where the friction coefficient is high and the adhesion regions are lower in the pad sample with MK-10 code. This shows that braking is more effective in the brake pad sample MK-10.

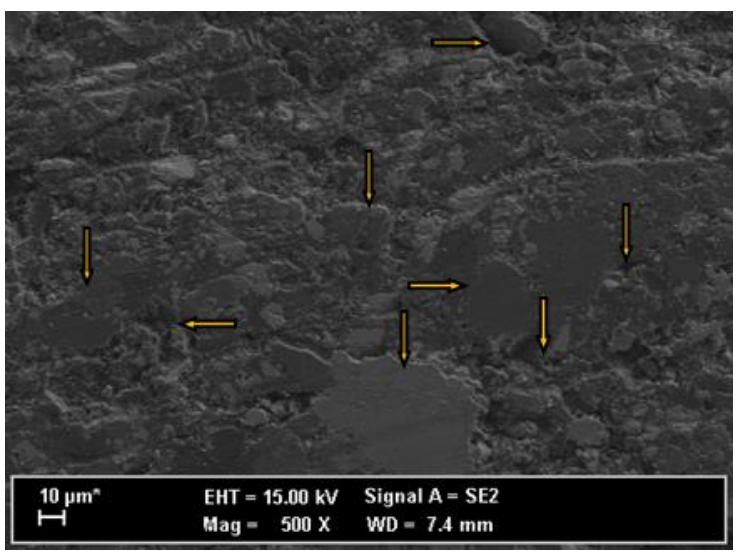

Fig. 6. SEM image of wear surface of MK-10 coded pad

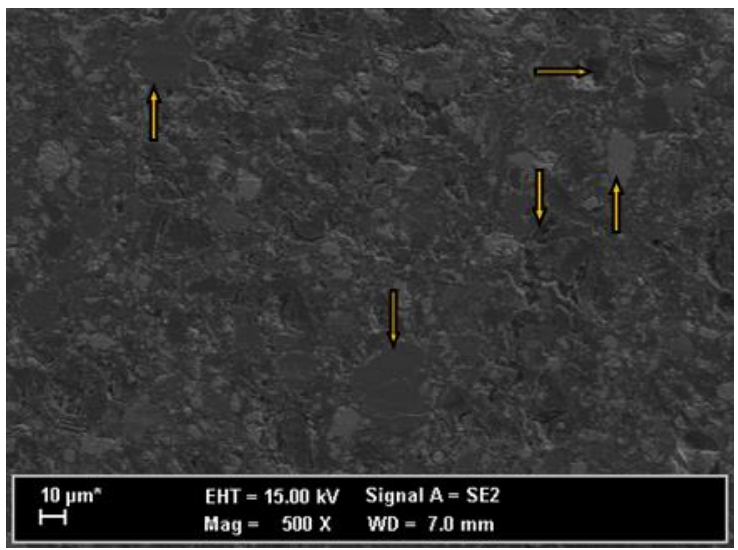

Fig. 7. SEM image of wear surface of MA-10 coded pad

\section{Conclusions}

In this study, two different pads containing banana peel powder and banana tree powder, which are alternative to the phenolic resin material used as a binder to keep the materials in the pad together, were evaluated by comparing the brake performance. As a result of the experiments;

- The use of banana peel powder together with the phenolic resin in the pad has a positive effect on the friction coefficient of the pad.

- The use of banana waste in combination with the phenolic resin in the pad has increased the friction stability by exhibiting a more stable friction coefficient.

- The use of banana tree bark powder and banana tree powder in combination with the phenolic resin has reduced the hardness of the pads.

- While the use of banana tree powder in the pad content decreases the density, the use of banana bark powder in the 
pad content increased the density.

- The use of banana peel powder and banana tree powder in the brake pad content will create a new field in the evaluation of waste products.

\section{References}

[1] Chandra, P., Menapace, V. L., Bonfanti, A., Ciudin, R., Gialanella, S., Straffelini, G. (2015). Braking pad-disc system: Wear mechanisms and formation of wear fragments. Wear, 322-323, 251-258.

[2] Jadhav S. P., Sawant, S. H. (2019). A review paper: Development of novel friction material for vehicle brake pad application to minimize environmental and health issues. Materials Today, 19(2), 209-212.

[3] Kukutschova, J., Roubícek, V., Malachova, K., Pavlíckova, Z., Holusa, R., Kubackova, J., Micka, V., Maccrimmon, D., Filip, P. (2009). Wear mechanism in automotive brake materials, wear debris and its potential environmental impact. Wear, 267(5-8), 807-817.

[4] Park, S. H. (2018). Types and health hazards of fibrous materials used as asbestos substitutes. Safety and Health at Work, 9(3), 360-364.

[5] Ahmadijokani, F., Shojaei, A., Dordanihaghighi, S., Jafarpour, E., Mohammadi, S., Arjmand, M. (2020). Effects of hybrid carbon-aramid fiber on performance of non-asbestos organic brake friction composites. Wear, 452-453, 203280.

[6] Jeganmohan, S., Sugozu, B., Kumar, M., Selvam, D.R. (2020). Experimental investigation on the friction and wear characteristics of palm seed powder reinforced brake pad friction composites. Journal of The Institution of Engineers (India): Series D, 101(1), 61-69.

[7] Singh, T., Tiwari, A., Patnaik, A., Chauhan, R., Ali S. (2017). Influence of wollastonite shape and amount on tribo-performance of non-asbestos organic brake friction composites. Wear, 386-387, 157-164.

[8] Sudhan Raj, J., Christy, T.V., Darius Gnanaraj, S., Sugozu, B. (2020). Influence of calcium sulfate whiskers on the tribological characteristics of automotive brake friction materials. Engineering Science and Technology, an International Journal, 23(2), 445-451.

[9] Singaravelu, D. L., Vijay, R., Filip, P. (2019). Influence of various cashew friction dusts on the fade and recovery characteristics of non-asbestos copper free brake friction composites. Wear, 426-427, 1129-1141.

[10]Sai Krishnan, G., Ganesh Babu, L., Kumaran, P., Yoganjaneyulu, G., Sudhan Raj, J. (2019). Investigation of Caryota urens fibers on physical, chemical, mechanical and tribological properties for brake pad applications. Materials Research Express, 7(1),015310.

[11]Aranganathan, N., Mahale, V., Bijwe, J. (2016). Effects of aramid fiber concentration on the friction and wear characteristics of non-asbestos organic friction composites using standardized braking tests. Wear, 354-355, 69-77.

[12]Raj Jeganmohan, S., Gnanaraj Solomon, D., Christy, T.V.
(2018). Effect of two different rubbers as secondary binders on the friction and wear characteristics of non-asbestos organic (NAO) brake friction materials. Tribology-Materials, Surfaces and Interfaces, 12(2), 71-84.

[13]Olabisi, A. I., Adam, A. N., Okechukwu, O. M. (2016). Development and assessment of composite brake pad using pulverized cocoa beans shells filler. International Journal of Materials Science and Applications, 5(2), 66-78.

[14]Ruzaidi, C. M., Kamarudin, H., Shamsul, J. B., Al Bakri, A. M. M., Rafiza, A. R. (2011). Comparative study on thermal, compressive, and wear properties of palm slag brake pad composite with other fillers. Australian Journal of Basic and Applied Sciences, 5(10), 790-796.

[15]Pujari, S., Srikiran, S. (2019). Experimental investigations on wear properties of Palm kernel reinforced composites for brake pad applications. Defence Technology, 15(3), 295-299.

[16]Namessan, N. O., Maduako, J. N., Iya, S. (2013). Comparative study of the effects of treatment techniques on the thermal and frictional properties of Kenaf (Hibiscus canabinus) fibre reinforced brake pads. African Journal of Science and Technology (AJST), Science and Engineering Series, 12(2), 44-54.

[17]Matejka, V., Fu, Z., Kukutschova, J., Qi, S., Jiang, S., Zhang, X., Yun, R., Vaculik, M., Heliova, M., Lu, Y. (2013). Jute fibers and powderized hazelnut shells as natural fillers in nonasbestos organic non-metallic friction composites. Materials \& Design, 51, 847-853.

[18]Aigbodion, V. S., Akadike, U., Hassan, S. B., Asuke, F., Agunsoye, J. O. (2010). Development of asbestos- free brake pad using bagasse. Tribology in Industry, 32(1), 12-18.

[19]Ibhadode, A. O. A., Dagwa, I. M. (2008). Development of asbestos-free friction lining material from palm kernel shell. Journal of the Brazilian Society of Mechanical Sciences and Engineering, 3(2), 166-173.

[20]Yawas, D. S., Aku, S. Y., Amaren, S. G. (2016). Morphology and properties of periwinkle shell asbestos-free brake pad. Journal of King Saud University, Engineering Sciences, 28(1), 103-109.

[21]Sugözü, İ. (2015). Investigation of using rice husk dust and ulexite in automotive brake pads. Material Testing, 57(10), 877-882.

[22]Sugozu, B. (2018). Tribological properties of brake friction materials containing fly ash. Industrial Lubrication and Tribology, 70(5), 902-906.

[23]TS 555. (1992). Highway vehicles, brake systems, brake pads for frictional brake.

[24]Barros, L. Y., Poletto, J. C., Neis, P. D., Ferreira, N. F., Pereira, C. H. S. (2019). Influence of copper on automotive brake performance. Wear, 426-427, 741-749.

[25]Österle, W., Urban, I. (2004). Friction layers and friction films on PMC brake pads. Wear, 257(1-2), 215-226.

[26]Bijwe, J., Kumar, M. (2007). Optimization of steel wool contents in non-asbestos organic (NAO) friction composites for best combination of thermal conductivity and tribo-performance. Wear, 263, 7-12, 1243-1248.

[27]Kim, J. W., Joo, B. S., Jang, H. (2019). The effect of contact 
area on velocity weakening of the friction coefficient and friction instability: A case study on brake friction materials. Tribology International, 135, 38-45.

[28]Joo, B. S., Jara, D. C., Seo, H. J., Jang, H. (2020). Influences of the average molecular weight of phenolic resin and potassium titanate morphology on particulate emissions from brake linings. Wear, 450-451, 203243.

[29]Jara, D. C., Jang, H. (2019). Synergistic effects of the ingredients of brake friction materials on friction and wear: A case study on phenolic resin and potassium titanate. Wear, 430-431, 222-232.

[30]Ertan, R., Yavuz, N. (2010). An experimental study on the effects of manufacturing parameters on the tribological properties of brake lining materials. Wear, 268(11-12), 1524-1532.

[31]Cai, R., Zhang, J., Nie, X., Tjong, J., Matthews, D. T. A. (2020). Wear mechanism evolution on brake discs for reduced wear and particulate emissions. Wear, 452-453, 203283.

[32]Kim, S. S., Hwang, H. J., Shin, M. W., Jang, H. (2011). Friction and vibration of automotive brake pads containing different abrasive particles. Wear, 271(7-8), 1194-1202. 